\title{
SISTEMATIZAÇÃO DO EXAME PSIQUIÁTRICO (*)
}

\author{
DR. J. CARVALHAL RIBAS \\ Assistente de Clínica Psiquiátrica da Faculdade de Medicina
}

\section{1 - ANAMNESE}

Deve-se assumir atitude prudente ao aproximar-se do doente e interrogá-lo do modo simples e insinuante, procurando conquistar-1he a confiança para que êle se manifeste mais exuberantemente. Conduzir a palestra com tacto e proveito, sem forçar o doente, prolongando o interrogatório, si necessário, até diversas sessões. Observar tudo quanto o doente manifestar durante a consulta, pois póde servir de informação acêrca do seu estado psíquico. Indivíduos sadios, simuladores concientes, procuram às vezes tirar proveito fingindo-se doentes, como acontece a operários acidentados sem consequências e desejosos de receber a indenização. Outros, simuladores inconcientes ou histéricos, apresentam distúrbios na ausência de lesão orgânica sem terem noção do próprio embuste. Outros realmente doentes, dissimuladores', têm interêsse em ocultar a moléstia, como procedem muitas pessoas desejosas de ingressar em companhias de seguro. Outros doentes são desconfiados e, porisso, reticentes. Outros, incapazes de dar esclarecimentos. Outros, em estado de mutismo. Outros recusam submeter-se a exame e, porisso, as famílias propõem às tezes ao alienista avistar-se com o paciente ocultando a qualidade de médico. O facultativo não deve adotar o ardil, pois perderá o pres-tígio junto ao cliente si fracassar o estratagema. No máximo, deve ir à casa do paciente sob pretexto de examinar outra pessoa e, em palestra com o verdadeiro doente, investigar seu estado psíquico. Não Bastam as declarações do paciente, a-pesar-do seu grande significado semiótico. Deve-se colher informações do caso junto dos que tenham convivido com o doente. As famílias omitem às vezes esclarecimentos porque têm vergonha de revelar a presença da loucura em casa. Pudor descabido! O cerebro, orgão susceptível de perturbar-se como qualquer outro, sofre distúrbios que devem ser confessados com sin

(*) Aula proferida em 12-2-941 no Curso de Propedêutica do Sistema Nervoso realizádo pelo dr. Oswaldo F. JULï̈., a convite do Departamento Cientifico do "Centro Aicademico Oswaldo Cruz".

Para maior conhecimento do assunto, consulte-se a "Psiquiatria Clínica e Forense" do. Prof. A. C. Pacheco E Silva. 
a mesma ausência de vexame com que as pessoas referem padecer do coração ou do fígado.

a) Identificação - Registar nome de doente, sexo, côr, raça, nacionalidade, estado civil, idađ̄e, grau de cultura, profissão, religião, residência, etc., afim de se evitarem equívocos de identidade, pois o exame psiquiátrico assume grave significado.

Êsses dados sugerem deduções de interêsse clínico. Em relação ao sexo, o homem apresenta psicopatias em geral decorrentes da sua vida de atividades exaustivas, preocupações e vícios (alcoolismo, paralisia geral, etc.), enquanto a mulher acusa principalmente distúrbios psíquicos ligados aos chóques fisiológicos que está fadada a sofrer, sobretudo por ocasião da maternidade (psicoses gravídicas, puerperais, da menopausa, etc.). Em relação ao estado civil, os solteiros apresentam desordens psíquicas mais frequentemente do que os casados, talvez porque o matrimônio realize ambiente de maior higiene mental. Em relação à idade, cada doença se instala de preferência em determinada época da vida (oligofrenias na infância, esquizofrenià na puberdade, alcoolismo, paralisia geral e parafrenia na idade madura, psicoses de involução na velhice, etc.) Em relação à raça, cada uma se mostra predisposta à instalação de certas psicopatias (idiotia amaurótica ña raça semita, esquizof renia na amarela, alcoolismo na negra, etc.). Em relação à profissão, o indivíduo está exposto a contrair certas psicoses de acôrdo com as circunstâncias a 'que fồr lançado pelo meio de vida (alcoolismo frequente nos que trábalham com bebidas, toxicomanias nos médicos e outros que tenham drogas ao alcance, paralisia geral nos militares cuja vida anti-higiênica facilita a aquisição da sífilis, psicoses tóxicas nos operários que manipulam chumbo, etc.).

b) Antecedentes hereditários - Apurar si os pais do doente encerram fatores que hajam influido na procriação de próle fadada à loucura e si a família acusa predisposição às neuro-psicopatias que se transmita através das gerações. . Quais as afecções de que os pais foram e ainda são portadores? Contrairam sífilis? Averiguá-lo por meio do interrogatório, presença de sinais clínicos nos pais, ocurrência de abortos espontâneos na progenitora, positividade de exames complementares, etc. Os pais têm sido etilistas inveterados?. Quando falecidos, quais as doenças que os vitimaram? Que moléstias têm ocorrido aos irmãos e parentes? A família conta casos de tuberculose, alcoolismo, neuro-psicopatias? A maioria dos psicopatas provem de famílias onde já se registaram casos de loucura, demonstrando ser a herança mórbida o maior fator predisponente às doenças mentais.

c) Antecedentes pessoais, passado pré-psicótico - Apurar fatos ocorridos até o início da doença ao indivíduo que hajam contribuido para torná-lo psicopata. A gestação do indivíduo foi perturbada por traumas físicos ou psíquicos, toxi-infecções e moléstias da progenitora? O parto foi prematuro, laborioso, com intervenção de- 
sastrada do forceps? Acidentes da gestação e do parto podem comprometer o desenvolvimento das faculdades mentais. O individuo demorou a sentar-se, andar, falar, reconhecer pessoas? Anomalias do desenvolvimento sômato-psíquico já podem anunciar o candidato à loucura. Onde e como foi educado? Ambiente de rixas, máus tratos e exemplos nocivos, proporcionando educação desleixada, extravagante, de qualquer maneira viciosa, póde concorrer para transtornar a mente. Frequentou escola com proveito e bom comportamento? O insucesso escolar denuncia muitas vezes o estado psíquico precário do indivíduo. Além das doenças peculliares à infância, teve outras que possam comprometer o psiquismo: encefalite, meningite, convulsões, coréia, traumatismos craneanos? Si se tratar de mulher, quando se deu a menarca e como se comporta o ciclo menstrual? Como tem decorrido a vida sexual do individuo? Distúrbios sexuais acarretam desordens psíquicas tão frequentes a ponto da escola psicanalítica admitir a libido como fundamento de importância capital na gênese das doenças mentais. Contraiu a sífilis causadora de transtornos mentais bastante posteriores? em que idade? quais os resultados dos exames complementares? fez tratamento adequado e suficiente? Si fôr casado, qual o estado de saúde do cônjuge? quantos abortos espontâneos teve a espôsa? O doente entregou-se ao alcoolismo e outras toxicomanias responsáveis por distúrbios da mente? Viveu sob ação de trabalhos exaustivos, preocupações, conflitos sociais, excessivo ruido e outros fatores responsáveis pela miopragia nervosa do homem civilizado?

Para orientar o diagnóstico, apurar qual era o caráter pré-psicótico do indivíduo, que já podia condicionar a instalação de determinada psicopatia. Antes da doença, o indivíduo era retraído, calado, indiferente ao meio, revelando constituição esquizotímica ou, em grau mais acentuado, esquizoide? Estava predisposto à esquizofrenia. Era -sujeito a alternativas de alegria, excitação, e de tristeza, depressão, revelando constituição ciclotímica ou, em grau mais acentuado, cicloide? Estava predisposto à psicose maníaco-depressiva. Assim o indivíduo ainda podia revelar outras constituições capazes de predispô-lo a contrair outros quadros psicopáticos: constituições emotiva, paranoide, pitiática, perversa, mitomaníaca, toxicófila, epileptoide, etc.

d) História da moléstia atual - Apurar tudo quanto o indivíduo venha manifestando de anormal desde o início da doença até o momento presente.

Quando começou a doença? Determina-se bem o início quando os distúrbios explodiram de modo súbito e espetaculoso; apenas vagamente quando a moléstia se instalou de modo insidioso e progressivo.

Qual foi a causa desencadeante da loucura? Preocupações, desgostos, abalos psíquicos em suma, podem fazer explodir desordens mentais desde que surpreendam o indivíduo já predisposto, como um 
terreno preparado à espera da semente. Distúrbios orgânicos também podem fazer sobrevir distúrbios da mente. Assim ocorrem perturbações mentais às vezes em consequência das grandes mutações fisiológicas inerentes a certas etapas da vida tais como puberdade, gravidez, parto, puerpério, menopausa, etc. Outras vezes, em consequência de traumatismos craneanos, infecções, sobretudo sífilis, intoxicações, em particular alcoolismo, afecções neurológicas, distúrbios das glândulas endócrinas e de quaisquer aparelhos.

Quais os primeiros sintomas que atrairam a atenção do paciente ou dos circunstantes? quais os seguintes? Descrevê-los pela ordem cronológica de aparecimento, devendo-se registar a interpretação psiquiátrica dos mesmos só por ocasião do exame psíquico. $\mathrm{O}$ indivíduo já apresentou distúrbio mental em época anterior? Apurá-lo da melhor maneira possível. Fazer interrogatório acêrca das condições dos diversos aparelhos, pois assim se poderão apurar, em quaisquer órgãos, perturbações responisáveis pelo desequilíbrio da mente.

\section{2 - EXAME SOMÁTICO}

a) Exame geral - Registar dados obtidos por um primeiro exame de conjunto do doente: estado da péle, panículo adiposo, musculatura, arcabouço ósseo, conformação craneana, estigmas degenerativos, mucosas, unhas, sistema piloso, dentes, língua, gânglios, altura, pêso, temperatura, esternalgia, tibialgia, etc. Para orientar o diagnóstico, verificar o tipo constitucional do indivíduo de acôrdo com a classificação de KRETSCHMER, que distribue a humanidade em quatro tipos: 1) leptosomático ou astênico, indivíduo esguio, de cabeça pequena, pescoço longo, corpo estreito e magro, torax e musculatura pouco desenvolvidos, membros compridos; 2) atlético, indivíduo de torax largo, arcabouço ósseo e musculatura bem desenvolvidos, bacia estreita, membros inferiores finos; 3) pícnico, indivíduo de aparência super-nutrida e baixa estatura, cabeça grande, pescoço curto e grosso, torax amplo e abdómen volumoso; 4) displásico, indivíduo de formas desproporcionadas e bizarras devido a distúrbios endócrinos. Os tipos leptosomático e atlético indicam predisposição à esquizofrenia; o tipo pícrico, predisposição à psicose maníaço-depressiva.

b) Exame dos aparelhos respiratório, cárdio-vascular, digestivo, gênito-urinário, glândulas endócrinas, órgãos sensoriais e sistema nervoso, de acôrdo com métodos propedêuticos adequados. Os exames endócrino e neurológico jamais devem ser omitidos, pois o estado psíquico se acha subordinado às glândulas de secreção interna e ao sistema nervoso $(*)$. O psiquiatra precisa ser um clínico capaz de surpreender e interpretar o que houver de anormal nos diversos departamentos da economia, pois transtornos orgâ-

(*) Para se efetuar o exame do sistema nervoso, consulte-se a "Sistematização do Exame Neurológico" do dr. Oswaldo F. Julin̈o, no mesmo numero dessa revista. 
nicos são muitas vezes os responsáveis pela sobrevinda de distúrbios mentais.

\section{3 - EXAME PSÍQUICO}

a) Exame geral - Registar dados obtidos por um primeiro exame de conjunto do doente:

Facies do doente - Alegre (mania, paralisia geral expansiva), arrogante (paranoia), desconfiado, ameaçador (parafrenia), triste, inquieto, abatido (melancolia, estados depressivos), embrutecido, indiferente, inexpressivo (confusão mental), podenido observar-se exagêro da mímica ou hipermimia (mania, melancolia ansiosa), diminuição da mímica ou hipomimia (melancolia depressiva), abolição da mímica ou amimia (confusão mental) e perversão da mímica ou paramimia, por exemplo assumindo o doente expressão alegre quando se acha triste (esquizofrenia, melancolia). A expressão mímica orienta o diagnóstico, pois denuncia o estado psíquico do indivíduo, a não ser quando estiver prejudicada em consequência de lesão orgânica.

Atitude do doente - Normal , amaneirada (esquizofrenia), satisfeita (mania, paralisia geral expansiva), altaneira (paranoia), desconfiada, colérica, agressiva (parafrenia), angustiada, apática (melancolia, estados depressivos), indiferente (confusão mental, esquizofrenia, etc.), com gesticulação acentuada (mania, melancolia ansiosa), ou diminuta (melancolia depressiva), ou nula (esquizofrenia, confusão mental, etc). O modo de apresentação orienta o diagnóstico, pois também traduz o estado mental do indivíduo.

Vestuário do doente - Bem compôsto, descuidado, em desordem (mania), excêntrico, com enfeites e emblemas (paranoia), etc. Orienta o diagnóstico, pois também deixa trair o estado mental da pessoa. Doentes com abolição dos sentimentos éticos se apresentam muitas vezes desnudos.

Fala do doente - Alterada em consequência de distúrbios neurológicos tais como afasias, disartrias, disfonias e dislalias, ou em consequência de comprometimento exclusivamente psíquico, que se traduz de diversas maneiras: O doente fala em tom alegre, sarcástico, obsceno, com exagêro de linguagem ou logorréia, às vezes rimando palavras (mania, paralisia geral incipiente). Em tom receioso e reticente (parafrenia). Em tom triste, queixoso (melancolia, estados depressivos). De modo dificil e vagaroso (estados depressivos, confusão mental, etc.). Fala sòzinho, em solilóquio, respondendo a alucinações, com risos e choros imotivados (esquizofrenia, parafrenia, etc.). Responde absurdamente às perguntas: sindromo de Ganser (esquizofrenia). Emprega neologismos, palavras incompreensíveis de sua própria invenção (índice de cronicidade da moléstia). Repete sempre uma palavra ou frase: estereotipia verbal ou verbigeração (esquizofrenia, mania, melancolia, confusão mental, etc.). Apenas ar- 
ticula palavras desconexas: salada de palavras (esquizofrenia, estados demenciais, etc.). Ou, então, finalmente, apresenta-se em estado de mutismo, por obediencia a alucinações, delírio de ruina, abulia, negativismo ou simulação.

Escrita do doente - Às vezes muito abundante denunciando exagêro da linguagem escrita ou grafomania (mania, parafrenia, paralisia geral incipiente, etc.), bem cuidada (parafrenia), desordenada (mania), acusando caligrafia bizarra, anotações extravagantes, repetição constante de certos sinais ou estereotipias gráficas (esquizofrenia), falhas relacionadas ao conteúdo ideativo, êrros psicográficos, ou fathas relacionadas à caligrafia, êrros caligráficos (paralisia geral, confusão mental, etc.). Cartas, testamentos, peças literárias e outros documentos do doente são elucidativos sob o ponto de vista psiquiátrico.

Ambiente do doente - Estado e disposição dos móveis no quarto, retratos, desenhos, livros, objetos de uso, condições de ordem e de higiene, detalhes do lugar que refletem a mentalidade do inquilino e, por conseguinte, orientam o diagnóstico.

b) Exame das faculdades mentais - Apurar si as faculdades de que se compõe a personalidade humana se encontram no paciente em estado normal ou patológico.

\section{ATENÇÃO}

A atenção permite ao homem convergir o espirito para o que lhe desperta interêsse em si mesmo e no exterior, de modo anárquico (atenção espontânea) ou de modo disciplinado (atenção voluntária).

Póde estar: exaltada, concentrando-se a mente sôbre dado objéto a ponto de esquecer os demais - hiperprosexia (estados depressivos, melancolia, paranoia, etc.). Diminuida, dificultando à mente atender aos fatos - hipoprosexia (estafa psíquica, histeria, etc.), às vezes estando diminuida apenas a atenção voluntaria e, ao contrario, a espontânea exaltada, atendendo o doente a tudo quanto se passa sem conseguir concentrar longamente o espírito sôbre qualquer fato (mania, embriaguez alcoolica). Abolida, impossibilitando a fixação do espírito sôbre os fatos - aprosexia (idiotia, estados demenciais, etc.).

Avalia-se o grau de atenção observando si o doente acusa, mais ou menos, a expressão de pessoa com espírito concentrado- músculo frontal contraido, olhos bem abertos e imóveis, boca entreabertá, rosto corado devido à congestão cefálica, com movimentos respiratórios reduzidos - e si consegue acompanhar o interrogatório sem se distrair, atendendo às perguntas e dando respostas adequadas: $\mathrm{O}$ exercício diário da clínica dispensa geralmente a medida rigorosa dos processos psíquicos por meio dos aparelhos e testes da psicologia experimental. 


\section{YERCEPÇÃO}

Quando o homem projeta a atenção sôbre dado objeto, os órgãos sensoriais recolhem impressões do objeto, que são conduzidas através das vias sensoriais à cortex cerebral. Devido às impressões aí se transformarem em sensações, o homem, então, ouve imprecisamente um som, vê indistintamente uma côr, experimenta vagamente um cheiro, um sabor, um contato, etc. Depois, devido às sensações se transformarem em percepções, identifica melhor o fato, informando-se que se trata do seguinte, por exemplo: o som de uma campainha, a côr vermelha de uns cravos, o cheiro de Agua de Colônia, o sabor de um bife, o contato de uma peliça, etc. $O$ homem recebe tambem impressões do pròprio organismó, que são trazidas através da via simpática aos centros nervosos superiores e dão lugar às sensações cenestésicas. Adquire assim apenas noção vaga do próprio organismo, pois o estado hígido se carateriza pelo relativo silencio das vísceras.

Os distúrbios da percepção são as alucinações e as ilusões, que se exploram principalmente por meio do interrogatório do doente e se encontram em quasi todas psicopatias (confusão mental, alcoolismo, esquizofrenia, parafrenia, histeria, psicoses de involução, etc.).

O doente apresenta alucinação quando está convicto de perceber um fato que não existe na realidade. Embora nada ocorra de fato, afirma perceber: ruidos, sons, vozes confusas ou inteligíveis de gente estranha ou conhecida, viva ou falecida, dirigindo-lhe conselhos, ordens, injúrias - alucinações auditivas. Ou então, clarões, sombras, visões de animais ou zoopsias, pessoas, almas do outro mundo, santos, monstros - alucinações visuais. Ou então, odores estranhos alucinações olfativas. Ou então, sabores inexistentes nos alimentos - alucinações gustativas. Ou então, contatos na péle - alucinações tácteis. Embora nada ocorra de anormal nos órgãos, afirma perceber, por exemplo, bichos no estômago, lacerações nos orgãos genitais, destruição ou inexistência de vísceras - alucinações cenestésicas. Embora não faça realmente movimentos, afirma perceber a execução de gestos, saltos, movimentos de escrita, articulação de palavras àlucinações motoras.

O doente apresenta ilusão quando percebe de modo errôneo o que existe na realidade. Percebe, por exemplo: um toque de sineța como si fosse um tiro de revólver - ilusão auditiva. Uma pessoa desconhecida como si fosse velho amigo - ilusão visual. Um perfume de rosas como si fosse a exalação de gases tóxicos - ilusão olfativa. $\mathrm{O}$ sabor de uma feijoada como si fosse gôsto de veneno - ilusão gustativa. Um mal-estar gástrico como si fossem rãs no estômago - ilusão cenestésica. Um movimento como si fosse outro diferente - ilusão motora. 


\section{MEMÓRIA}

O homem grava na mente os fatos percebidos (memória de fixa$\varsigma \tilde{a} o$ ), armazena-os durante tempo indeterminado (memória de conservação) e recorda-os mais tarde (memória de evocação), com a. noção da data de sua ocurrência (memòria de localização cronológica).

A memoria póde estar: exaltada, recordando o individuo até fatos da primeira infância - hipermnésia (estados febris, mania, etc.). Diminuida, dificultando a fixação, conservação e evocação de fatos - hipomnésia (cansaço, confusão mental, paralisia geral, psicastenia, etc.). Abolida desde o nascimento do individuo - amnésia congênita (oligofrenias), ou abolida mais tarde, de modo parcial ou geral, transitório ou definitivo - amnésia adquirida (traumatismos físicos ou psiquicos, confusão mental, paralisia geral, epilepsia, estados demenciais, etc.). Pervertida, sobrevindo êrros e desvirtuamentos de recordações - paramnésia (histeria, psicoses de involução, etc.). O doente afirma nunca haver presenciado o que já assistiu (ilusão do "jamais vu") ou já haver presenciado o que nunca assistiu (ilusão do "déjà vu").

Avalia-se o estado da memoria averiguando si o doente consegue dar o nome, idade, detalhes do seu passado e da familia, e interrogando-o si se lembra bem das coisas, não esquece onde guarda objetos, não deixa de fazer algo por esquecimento, etc. A família também poderá relatar episódios reveladores do estado da memória do doente.

\section{IMAGINAÇÃO}

A ìmaginação permite ao homem fazer figurar no espírito os fatos sem que coisa alguma esteja impressionando os sentidos na ocasião, conseguindo assistir apenas mentalmente episódios tão nitido como se estivessem ocorrendo no exterior. Assim o indivíduo póde desapegar-se do contato da realidade e construir ao bel-prazer um mundo interior àparte, às vezes absurdo e inverosímil.

A imaginação exaltada constitue a mitomania, que se investiga por meio do interrogatório do doente e se encontra em diversos quadros psicopáticos (histeria, mania, paralisia geral, alcoolismo, confusão mental, loucura moral, psicoses de involução, etc.). $\mathrm{O}$ mitomano, apenas por interêsse esportivo, inventa enredos e intrigas, proclamando-se capaz de extraordinárias proezas, autor de crimes célebres, vítima de doenças e de práticas lúbricas, engendrando calúnias contra os outros, denunciando-os falsamente como criminosos, etc.

\section{ASSOCIAÇÃO DE IDEIAS}

Quando um fato acode à mente por qualquer motivo, o fatơ faz evocar outros fatos relacionados de qualquer maneira ao pri- 

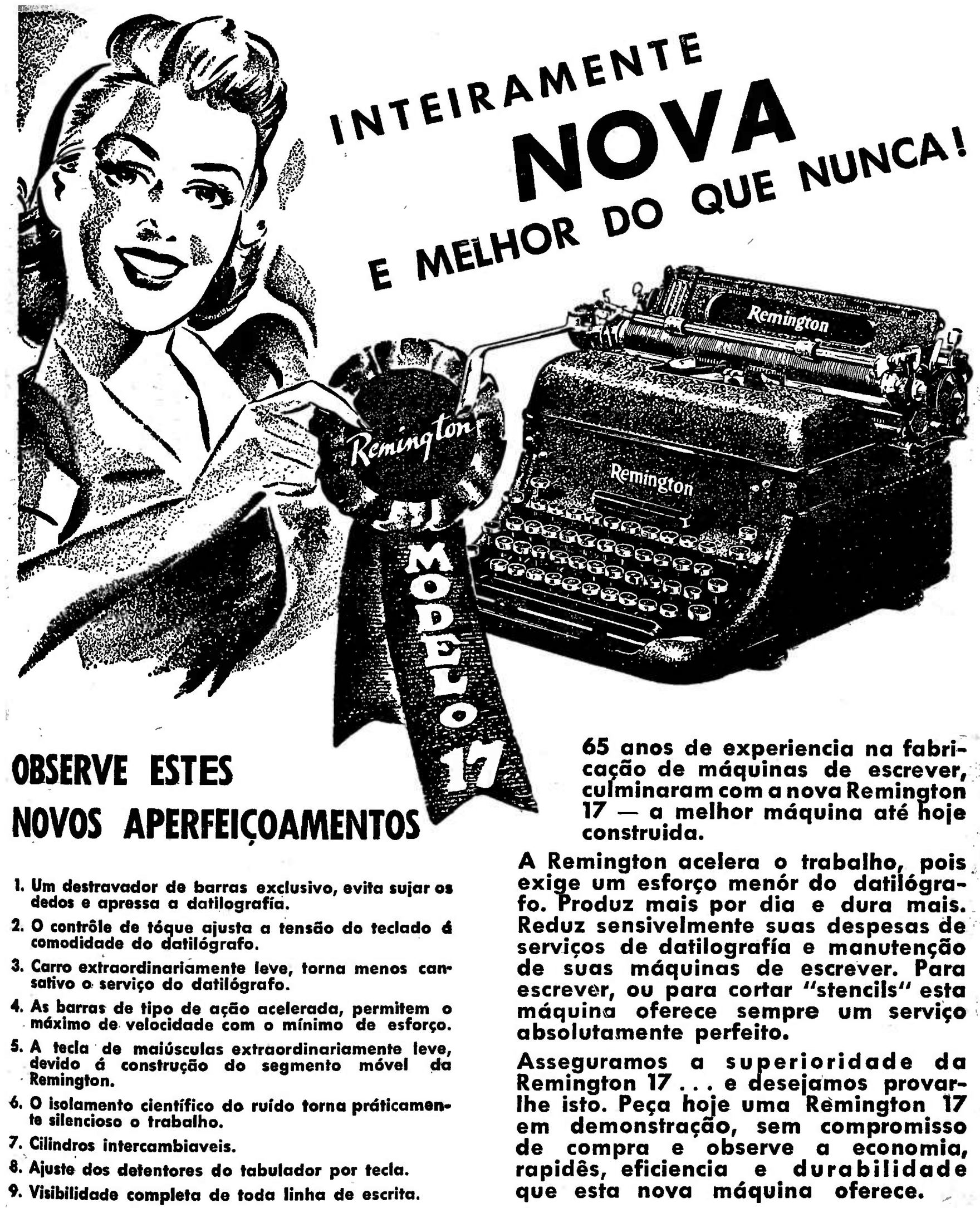
HOR 


\section{Uma organisação modelar a serviço da medicina}

Tudo o que V. S. necessitar para a instalação e a modernisação do seu consultorio ou da sua clinica, o poderá encontrar. em nossa casa.

A grande aceitação dos nossos artigos é devida não só á excelencia da sua qualidade, mas tambem ao modelar serviço de assistencia técnica, sempre pronto para servi-lo.

Fornecemos :

Instalaçõés radiologicas de todás as capacidades, inteiramente protegidas, para diagnostico e terapia. Aparelhos e tubos para todas as capacidades e fins. Mesas radiologicas universais e especialisadas para diagnostico e terapia. Aparelhos e acessoriós para a terapia pelas ondas curtas e para eletrocirurgia. 'Lampadas de raios ultravioletas e infravermelhos. Eletrocardiografos.

Sortimento completo de instrumentos cirurgicos. Moveis cirurgicos. Mesas para alta cirurgia. Lampadas para campo operatorio. Autoclaves e instalações completas de esterilisação.

Artigos para labóratorio. Vidraria e porcelanas. Reagentes. Balanças analiticas. Estufas. Centrifugas. Microtomos e microscopios. Colorimetros. Bombas de vacuo.

Aparelhos eletrodentarios de toda especie. Raios $\mathrm{X}$ dentarios. Equipos completos. Motores e tórnos. Aparelhos de diatermia. Instrumentos e miudezas em geral.

Faça-nos uma visita e convença-se de que tudo fazemos para bem servir a distinta classe medica do Brasil.

\section{CASA LOHNER}

\section{S. A. Médico - Técnica}

RIO DE JANEIRO

Av. Rio Branco, 133

Telefone, 23-5863
SÃO PAULO

Rua São Bento, 216

Telefone 3-2175

Telegr.: RE NO L 
meiro, estabelecendo-se assim a associação de idéias. As idéias se sucedem umas às outras em marcha de velocidade maior ou menor e em quantidade susceptível de avaliar-se pelo número de palavras do indivíduo para manifestá-las.

A associação ideativa póde estar acelerada (mania, paralisia geral incipiente, etc.), afluindo as idéias de modo excessivo a ponto do indivíduo, embora falanido incessantemente, não achar tempo para expressá-las por completo e deixar as frases sem concluir - fuga de idéias (mania). Ou então, vagarosa, obrigando o doente a falar de modo pausado - bradipsiquia ou viscosidade mental (estados depressivos, confusão mental, alcoolismo, epilepsia, etc.). Às vezes, a marcha ideativa até sofre breve interrupção, logo depois conseguindo o doente prosseguir a conversa - interceptação do pensamento (esquizofrenia). Outras vezes, a marcha ideativa até se torna desconexa e incoerente, exteriorizando-se pela salada de palavras (esquizofrenia, estados demenciais, etc.).

\section{JULGAMENTO E RACIOCÍNIO}

Depois de reunir e relacionar as idéias, o homem consegue formar juizos ou julgamentos acêrca das coisas, tais como por exemplo: "os seres vivos são mortais", "o homem é um ser vivo", etc. Depois o homem ainda estabelece relações entre os juizos e daí conclue novos juizos. Tal processo constitue o raciocinio, que permite adquirir-se o conhecimento sem intervenção da percepção, apenas à custa de mecanismo lógico, possibilitando ao homem até a previsão de fatos. Assim, de posse dos juizos "os seres vivos são mortais" e "o homem é um ser vivo", chega-se a outro juizo, por raciocínio: "o homem é mortal".

O julgamento perturbado constitue o delírio, que consiste no indivíduo julgar-se em condições diferentes das que se encontra na realidade. $\mathrm{O}$ delírio se estabelece à custa de alucinações - delírio de percepção imediata. Por exemplo, o doente convicto de ouvir vozes ameaçadoras acaba por julgar-se perseguido, construindo assim um delírio de perseguição. Às vezes o delírio se estabelece através do raciocínio - delirio de inferência ou interpretativo. Por exemplo, o doente, já portador do delírio de perseguição, raciocina que, si as pessoas perseguidas são geralmente grandes personagens e êle está sendo perseguido, êle deve ser grande personagem, construindo assim um delírio de grandeza. Finalmente, o delirio às vezes se estabelece à custa da imaginação - delírio de imaginação. $\mathrm{O}$ inldivíduo, em virtude da imaginação exaltada, fantasia-se em situaçõos extraordinárias, construindo assim um julgamento em desacôrdo com a realidade.

Exploram-se os delírios por meio do interrogatório do doente e das informações da família, apurando-se si o indivíduo se julga em condições diferentes das que se acha na realidade. $O$ doente acusa 
muitas vezes apenas a idéia fixa, uma idéia falsa em relação a dada coisa e, convencido da exatidão da idéia, bate-se pela realização da mesma. Quando se desenvolve e se estende a idéia fixa, estabelecem-se as idéias delirantes, daí resultando julgamentos errôneos ou delírios. Sempre em desacôrdo com a realidade dos fatos, o doente julga-se miserável, indigno, culpado de crimes, merecedor de castigo, perdido - delírio de ruina, auto-acusação (melancolia, paralisia geral depressiva, etc.). Julga-se perseguido por inimigos desejosos de roubar-lhe direitos, deshonrá-lo, matá-lo - delírio de perseguição (parafrenia, paranoia, esquizofrenia, etc.). Julga-se muito rico, inteligente, forte, belo, bondoso, nobre - delírio de grandeza ou megalomaníaco (paralisia geral expansiva, mania, paranoia, parafrenia, etc.). Julga-se gravemente doente, em decomposição - delírio hipacondríaco (melancolia, paralisia geral depressiva, psicoses de involução, etc.). Julga que não existem seus próprios órgãos, as pessoas, a terra, os astros - delírio de negação (melancolia, paralisia geral depressiva, confusão mental, etc.). Julga-se possuido por Deus ou pelo demônio, um apóstolo, um Messias - delírio místico ou religioso (paranoia, histeria, esquizofrenia, etc.). Julga-se acusado de perversões sexuais, vítima de práticas lúbricas, com gravidez imaginária - delírio erótico (histeria, parafrenia, psicoses de involu-. ção, paralisia geral incipiente, mania, etc.). Julga-se transformado em pau, vidro, outras substâncias, em animal - delírio de transformação corporal (melancolia).

\section{CONCIENCIA - ORIENTAÇÃO AUTO E ALOPSÍQUICA}

$\mathrm{O}$ homem, devido à sinergia existente entre todos setores do organismo, somática e psiquicamente, constitue um blocò unico e indivisível, a personalidade, susceptível de alterar-se no decurso das psicoses (transformações, desdobramentos, etc.).

Mas o homem não se informa de tudo quanto se passa na própria personalidade. Toma conhecimento apenas dos fatos que forem percebidos, apropriados de modo pessoal e arquivados na memória. Tais fatos permitem ao indivíduo saber quem seja (orientação autopsíquica) e onde se encontra no espaço, no tempo e no meio (orientação alopsíquica). Dão ao homem a noção exata da própria personalidade e do mundo exterior, o que constitue a conciência. Porisso, chamam-se fatos concientes. Os demais fatos são apenas suspeitados (fatos sub-concientes) ou se passam ignorados pelo homem (fa!os inconcientes).

A conciencia pode estar aumentada, acusando o indivíduo noção demasiado extensa da personalidade e do mundo exterior devida an exagêro das emoções, hipersensibilidade das vísceras, etc. Pode estar diminuida, acusando o indivíduo apenas noção imprecisa de si mesmo e do exterior (confusão mental, etc.). O doente aí apresenta desorientação auto-psíquica, parcial ou.completa, conforme fôr inca- 
paz de responder a alguma ou a todas perguntas acêrca do seu nome, idade, estado civil, etc. Apresenta desorientação alopsíquica, parcial ou completa, conforme fôr incapaz de responder a alguma ou a todas perguntas acêrca do lugar onde se encontra, data do dia, etc. A conciência pode estar abolida, perdendo o indivíduo toda noção da personalidade e do exterior e, portanto, tornando-se inconciente (sono normal, sem sonhos; estado de coma). Finalmente, a conciência pode estar alterada em virtude do indivíduo acusar noção errônea da personalidade e do mundo exterior. Isso sucede quando houver comprometimento de algum dos processos psíquicos de que resulta a conciência. Assim distúrbios da percepção, da apropriação pesşoal e da memória impedem o indivíduo de conhecer exatamente a si mesmo e o exterior e, portanto, tornam-no inconciente sem abolir-lhe muitas vezes a coerência em vista do seu raciocínio continuar a fazer-se mesmo partindo de noções falsas.

\section{INTELIGÊNCIA}

As faculdades acima enumeradas, inclusive a linguagem, faculdades ditas inteletuais, conferem ao homem a inteligência, quer dizer a capacidade de conhecer. A medida que o indivíduo avança em anos e assim adquire maior idade cronológica, ele desenvolve paralelamente a inteligência e assim adquire maior idade mental.

A inteligência pode acusar desenvolvimento atrazado ém relação ao número de anos que conta o indivíduo, tornando-se assim a idade mental inferior à idade cronológica, conforme ocorre nas oligofrenias. $O$ oligofrênico é idiota quando apenas consegue satisfazer os testes Binet-SIMON correspondentes à idade mental própria do indivíduo abaixo de três anos: dar o nome e sobrenome, mostrar olhos, nariz e bôca, etc. E' imbecil quando consegue satisfazer os testes BINETSrmon correspondentes à idade mental propria do individuo entre três 'e sete anos: dizer o sexo, nomear objetos usuais, distinguir manhã e tarde, definir objetos pelo uso, etc. E' debil mental quando já consegue satisfazer os testes BINET-SIMON correspondentes à idade mental própria do indivíduo entre sete e doze anos: dar a data do dia, reconhecer moedas, enumerar os meses, etc. A inteligência também pode desenvolver-se normalmente e depois sofrer rebaixamento em consequência de psicopatia, de modo profundo nos estados demenciais. Finalmente, a inteligência pode desenvolver-se de modo exagerado, tornando-se a idade mental superior à idade cronológica, conforme ocorre nos indivíduos supra-normais, gênios.

\section{AFETIVIDADE - EMOTIVIDADE}

Graças às faculdades afetivas ou afetividade, o homem imprime ao que conhece uma tonalidade de prazer ou de dôr, condicionando tais oscilações o estado de humor. Quando o indivíduo procede de acôrdo com tendências hereditárias ou adquiridas à custa do habito, 
manifesta-se o prazer e, em caso contrário, a dôr. Sob influência das tendências, o homem experimenta, em relação a isso ou àquilo, os sentimentos, estados afetivos duradouros e pouco intensos, tais como amor próprio, egoismo, humildade, amor aos animais, ao belo, etc. Experimenta taníbém sentimentos éticos de acôrdo com as noções de bem e de mal ,de dignidade, de pudor, que são estabelecidas pelas faculdades morais e se desenvolvem no convívio social. Deante de acontecimentos inesperados aos quais não consegue se adatar incontinenti, o homem experimenta emoções, estados afetivos transitórios e violentos, tais como alegria, tristeza, ansiedade, medo, cólera, etc. Finalmente, o homem pode experimentar paixões, estados afetivos. sempre exaltados e duradouros, muitas vezes já de cunho patológico, tais como a paixão amorosa, ciumenta, religiosa, avareza, etc.

A afetividade pode estar exaltada. O doente acusa em grau exagerado quaisquer estados afetivos, por exemplo: o amor próprio, constituindo a autofilia ou egolatria (paranoia, esquizofrenia, parafrenia, etc.), o egoismo (demência senil, mania, etc.), a satisfação, constituindo a euforia (paralisia geral expansiva, mania, etc.), a prodigalidade (paralisia geral), a tristeza (melancolia, estados depressivos), a desconfiança (parafrenia, paranoia, etc.), a cólera (epilepsia, esquizofrenia, etc.). Acusa às vezes brusca transição da alegria para a tristeza e vice-versa - labilidade de humor (psicose maníaco'depressiva, paralisia geral, confusão mental, etc.). A afetividade póde estar diminuida ou abolida - anestesia afetiva (esquizofrenia, estados demenciais, etc.). Segundo relato da família e observação do proprio médico, o doente se mostra indiferente aos acontecimentos e deixa de interessar-se pelas pessoas, conforme às vezes até confirma quando interrogado a respeito, continuando impassível quando se experimenta, por exemplo, notificar-lhe a morte de alguem da família. Não oferece relutância si se fizer menção de despí-lo em público, quando estão também abolidos os sentimentos éticos. Às vezes.acusa ausência da noção de bem e de mal - amoralidade (loucura moral, estados atípicos de degeneração). Finalmente, a afetividade pode estar pervertida. O doente aborrece pessoas dignas de sua estima, os pais por exemplo, e faz convergir o afeto sôbre pessoas estranhas, animais (esquizofrenia).

Os distúrbios da emotividade são as obsessões (melancolia, psicastenia, estados depressivos). O doente aí apresenta o estado ansioso - inquietação, angústia pré-cordial, sensação de morte iminente, tremores, etc. Apresenta tal estado porque tem fobias, receios infundados em relação a seja o que fồr (obsessões fóbicas) ou porque tem idéias obsidentes, idéias que o indivíduo experimenta em forma paroxística, reconhece serem absurdas, tenta angustiosamente repelir e, depois de dissipadas, deixam-no aliviado (obsessões ideativas).

Exploram-se a afetividade e a emotividade por meio das declarações do doente e da família, inspecção do facies, atitude, vestuário 
e modo de falar do indivíduo, exame dos fenomenos somáticos concomitantes, etc.

\section{VONTADE - ATIVIDADE}

De acôrdo com o que conhece, experimenta de prazer ou de dôr e qualifica de bom ou máu, o homem estabelece a preferência a reagir dessa ou daquela maneira, manifestando assim a vontade. Depois reage efetivamente por meio de atos conforme sua vontade, manifestando assim a atividade voluntária. A maneira de conduzirse o homem de acôrdo com as tendências, a vontade, sobretudo convicções de moral, constitue o carater, que empresta cụnho todo pessoal a cada indivíduo. Alguns atos voluntários, depois de repetidos, tornam-se atividade automática, pois se realizam involuntariamente, embora a vontade possa intervir a qualquer momento e modificá-los, conforme ocorre à marcha, mímica, mastigação, deglutição, fala, escrita, respiração, etc. Por meio do automatismo, realizam-se atos sem intervenção da conciência e da vontade, inclusive atos estritamente da vida psíquica (automatismo mental). Mímica, fala e escrita, em virtude de servirem à expressão de estados afetivos e idéias, constituem modalidades da linguagem. Obras de arte e outras produções quaisquer também traduzem o que sente e pensa o homem; daí seu valor semiótico. Muitos atos complexos também se realizam sem prévio aprendizado, de modo inconciente e hereditário, baseados nos instintos de nutrição, conservação, reprodução e outros, constituindo a atividade instintiva. Outros atos mais simples também se realizam sem prévio aprendizado, de modo inconciente e hereditário, unicamente em resposta a dado estímulo, constituindo a atividade reflexa. Seu estudo pertence à neurologia e seus distúrbios, não raros nos quadros psicopáticos, devem ser pesquizados ao examinar-se o sistema nervoso.

A vontade pode estar exaltada - hiperbulia. O doente deseja realizar tudo que the acode ao espírito, desenvolvendo atividade excessiva e desordenada, sendo a excitação motora geralmente concomitante à excitação dos processos mentais - agitação psico-motora (mánia, confusão mental, exagêro de emoções, etc.). A vontade pode estar diminuida - hipobulia. O doente se torna vagaroso, indolente, deprimido (cansaço, desnutrição, estados depressivos, etc.). A vontade pode estar abolida - abulia. O doente é incapaz de qualquer esfôrço psíquico (abulia inteletual), ou de qualquer movimento (abulia motora ou barragem), ou de ambas as eventualidades, às vezes atingindo grau extremo o comprometimento volitivo - ivercia, estupor, torpor (confusão mental, esquizofrenia, etc.). Finalmente, a vontade pode estar pervertida - parabulia. O doente deseja realizar um ato e depois deseja fazer o contrário, sem chegar à decisão definitiva - ambivalência (esquizofrenia). Outras vezes, pratica impulsões, atos sem causa externa, desencadeados em forma de paroxis- 
mo, raramente inconcientes, que o indivíduo em geral não consegue reprimir embora reconheça serem inconvenientes, tais como impulsões aos tiques, emissão de palavras, destruição de objetos; roubo ou cleptomania, incêndio ou piromania, ingestão de alcool ou dipsomania, fuga, atos sexuais, homicídio, auto-mutilações, suicídio, etc. Outras vezes, o doente permanece sempre no mesmo lugar, mantem a mesma atitude, repete a mesma palavra, faz o mesmo movimento - impulsões motoras ou estereotipias (esquizofrenia). Denota, outras vezes, modo afetado nas atitudes, palavras, e gestos - maneirismos au amaneiramentos (esquizofrenia).

$\mathrm{O}$ doente se torna demasiado susceptível às solicitações e realiza docilmente tudo que se the propõe quando fôr vítima de exagerada influenciabilidade volitiva, acarretando-lhe sugestibilidade, passividade. Obedece invariavelmente à ordem de mostrar a língua embora sempre receba uma alfinetada na lingua ao submeter-se à experiencia - sinal de Kraepelin (esquizofrenia). Permanece em qualquer posição que se lhe imprimir - "flexibilitas cerea", catatonia, catalepsia (esquizofrenia). Repete a mímica, as palavras e os atos dos outros - ecomimia, ecolalia e ecopraxia (esquizofrenia). Faz automaticamente o que se lhe ordena, conforme se verifica atravez do hipnotismo. Por meio do automatismo patológico, procede de modo ignorado por si próprio, como ocorre na escrita automática, automatismo ambulatório, sonambulismo (epilepsia, histeria, etc.). O doente, ao contrário, permanece indiferente às solicitações, em estado de estupor, ou até realiza o inverso do que se 1 he propõe, em negativismo, quando houver diminuição da influenciabilidade volitiva (esquizofrenia).

De acôrdo com o quadro psicopático, o indivíduo pode manifestar a atividade mais diversa, conciente. ou inconciente, voluntária ou involuntária, conforme se consegue apurar por meio da anamnese do doente e da sua conduta. Pode manifestar, em relação ao instinto de nutrição: apetite exagerado ou bulimia, recusa ao alimento ou sitofobia, impulsão ao alcool ou dipsomania, etc. Em relação ao instinto de conservação: fobias, indiferença às variações do meio ou desvulnerabilidade, auto-mutilações, suicídio, etc. Em relação ao instinto genésico: intenso desejo sexual, satiríase no homem e ninfomania na mulher, frigidez, perversões sexuais. Em relação à disposição para o trabalho ou capacidade pragmática: atividade excessiva, incapacidade do desempenho da profissão, inércia, etc. Em relação ao instinto de propriedade: avareza, prodigailidade, destruição, colecionismo, cleptomania, etc. Em relação aos sentimentos familiares e sociais: inadaptabilidade, conduta excêntrica, misantropia, fugas, vagabundagem, revolta contra os demais, impulsos agressivos, atentados contra a família, uxoricídios, homicídios, magnicídios, suicídios coletivos, etc. Em relação aos sentimentos religiosos: preocupações místicas exageradas, superstições, fanatismo religioso, delírio messiânico, etc. Em relação aos sentimentos estéticos: peças literarias, desenhos, es- 
culturas e outras obras revestidas de carater morbido e comparáveis às manifestações artísticas dos povos primitivos e das crianças.

\section{4 - EXAMES COMPLEMENTARES}

Em vista da possibilidade de qualquer afecção repercutir sôbre o cerebro e acarretar distúrbios mentais, o psiquiatra, no intuito de apurar a etiologia do caso, além de fazer o exame clínico do doente, deve solicitar exames complementares de acôrdo com a necessidade de maior informação que sugere cada caso: reações de Wassermann, Kahn e outras no sangue, exames liquórico, radiológico, neuro-ocular, neuro-oto-rino-laringológico, hematológico, metabolismo basal, etc. $\mathrm{O}$ exame do líquido céfalo-raquidiano (*) se impõe frequentemente para se identificar o comprometimento do sistema nervoso (sífilis nervosa, paralisia geral, cisticercose cerebral, tumores cerebrais, etc.).

\section{5 -. SÚMULA}

Enumerar sucintamente os dados positivos apurados na anamnese, exame somático, exame psíquico e exames complementares, no intuito de se obter o esquema do caso e facilitar a discussão do diagnóstico.

\section{6 - DIAGNÓSTICO - PROGNóstico - ASSISTÊNCIA - TERAPÊUTICA}

Ou o individuo é normal, no caso de estar íntegro o psiquismo, ou fronteiriço, no cașo do estado psíquico já fora do normal ainda não constituir verdadeira loucura, ou psicopata, no caso de haver evidente prejuizo das faculdades mentais. Classificar-se-á o quadro mórbido de enfraquecimento psíquico quando fôr discreto e curável. Ṕsicose quando constituir doença mental susceptível de evolução. Enfermidade mental quando fôr comprometimento imutável e irremovível da mente. Alienação mental quando o indivíduo houver perdido a conciência, oferecendo perigo a si mesmo e à sociedade, tornando-se irresponsável pelos desatinos que cometer. Estado demencial ou demencia quando houver decadência profunda e definitiva das faculdades mentais, susceptível de ocorrer na fase final das psicoses, reduzindo o doente à vida estritamente vegetativa.

Distinguem-se diversas entidades nosográficas no que se chama a loucura e, em vista disso, fizeram-se classificações no intuito de se ordenarem os quadros estabelecidos pela Psiquiatria. A classificação da Sociedade Brasileira de Neurologia, Psiquiatria e Medicina

(*) Acêrca do exame iiquórico, consulte-se "O líquido céfalo-raquidiano em semeiologia Acerca do exame "Revista Clinica de S. Paulo" vol. IV - n. ${ }^{\circ} 2$ - Págs. 51 a 67$)$, ou "O líquido céfalo-raquidiano em clínica", livro do Prof. Oswaldo Lange. 
Legal, adotada entre nós, enfeixa as doenças mentais nos catorze grupos seguintes:

1 - Psiçoses infecciosas.

2 - Psicoses auto-tóxicas.

3 - Psicoses hétero-tóxicas (alcoolismo, morfinomania, cocainomania, etc.).

4 - Demência precoce ou esquizof renia.

5 - Delírio sistematizado alucinatório crônico - Parafrenia.

6 - Paranóia.

7 - Psicose maníaco-depressiva. Formas maníaca predominante, depressiva predominante e mixta.

8 - Psicoses de involução.

9 - Psicoses por lesões cerebrais e demências terminais (arterioesclerose, sífilis, etc.).

10 - Paralisia geral.

11 - Psicoses epiléticas.

12 - Psicoses ditas nevrósicas (histeria, neurastenia, psicastenia, coréia).

13 - Outras psicopatias constitucionais (estados atípicos de degeneração).

14 - Imbecilidade e idiotia (oligofrenias).

De acordo com os dados obtidos no exame do psicopata, às vezes só posșíveis depois de observação demorada, identifica-se a entidade nosográfica em jogo no caso. Depois de feito o diagnóstico, estabelecem-se o prognóstico e a terapêutica adequada. O doente ficará sob contrôle médico no próprio domicílio ou então, devido às exigências do seu tratamento ou às suas condições incompatíveis com o meio familiar e social, será internado em hospital especializado.

\section{SISTEMATIZAC̨ÃO DO EXAME PSIQUIÁTRICO}

\section{1 - ANAMNESE}

a) Identifiçação.

b) Antecedentes hereditários: Existência de tuberculose, sífilis, alcoolismo, neuro-psicopatias, na família.

c) Antecedentes pessoais, passado pré-psicótico: Condições de gestação, parto, desenvolvimento sômato-psiquico, anibiente, educação, escolaridade; moléstias peculiares à infância e outras; menarca, ciclo menstrual, vida sexual; passado venéreo-luético; alcoolismo, toxicomanias; trabalho exaustivo, preocupações, conflitos sociais, ruido excessivo, etc. Constituição mental do indivíduo.

d) História da moléstia atual: Início da doença. Causas psíquicas e orgânicas. Descrição dos sintomas. Notícia de distúrbios mentais em época anterior. Interrogatório acêrca dos aparelhos. 


\section{2 - EXAME SOMÁTICO}

a) Exame geral: Tipo constitucional de acôrdo com a classificação de Kretschmer.

b) Exame dos aparelhos: Exames endócrino e neurológico.

$$
3 \text { - EXAME PSÍQUICO }
$$

a) Exame geral: Facies, atitude, vestuário, fala, escrita e ambiente do doente.

b) Exame das faculdades mentais: Atenção, percepção, memória, imaginação, associação de idéias, julgamento, raciocínio, conciência, orientação auto e alopsíquica, inteligência, afetividade, estado de humor, emotividade, vontade, atividade.

\section{4 - EXÁAMES COMPLEMENTARES}

Reações de Wassermann, ide Kahn e outras no sangue, exames liquórico, radiológico, neuro-ocular, neuro-oto-rino-laringológico, hematológico, metabolismo basal, etc.

$$
\begin{gathered}
5 \text { - SÚMULA } \\
6 \text { - DIAGNÓSTICO - PROGNÓSTICO - ASSISTENCIA - } \\
\text { TERAPEUTICA. }
\end{gathered}
$$

\section{CARDIOSCLEROL TONICO CARDIACO ATOXICO HIPERTENÇÃO ARTERIAL - MIOCARDITES - ARTERIOESCLEROSE A base de Viscum album - Cactus grandiflora - Cratoegus - Kola - Scila - Rodanato de Potassa \\ Amostras e literaturas a disposição dos srs. Medicos}

CAIXA, 4500 INSTITUTO CHIMORGAN SÃo PAULO 


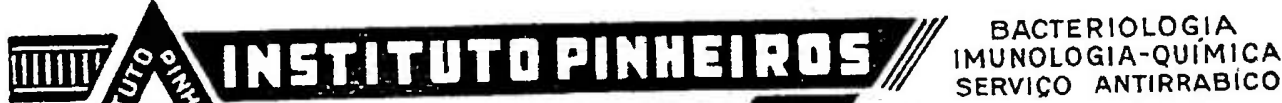 SIlP SAO PAUIO: CAIXA POSTAL, $95 ?$ EraTelegr.WZZITATelefones:82121}

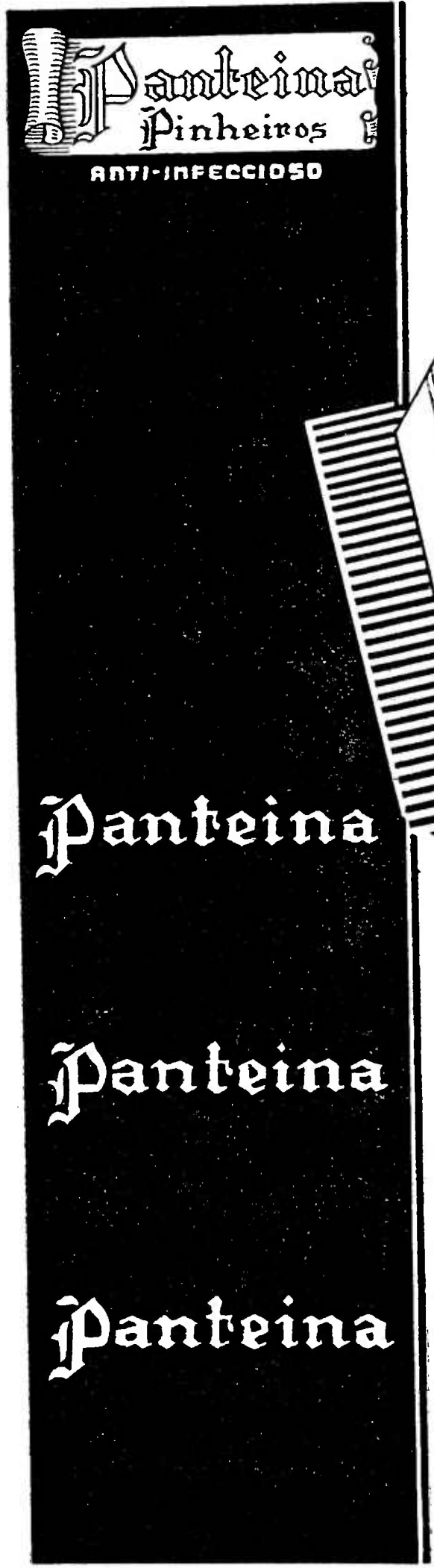

Rëterobactèriaterapea por lise parcial de cocos, difteróides,

$$
\text { capsulados. }
$$

\section{so}

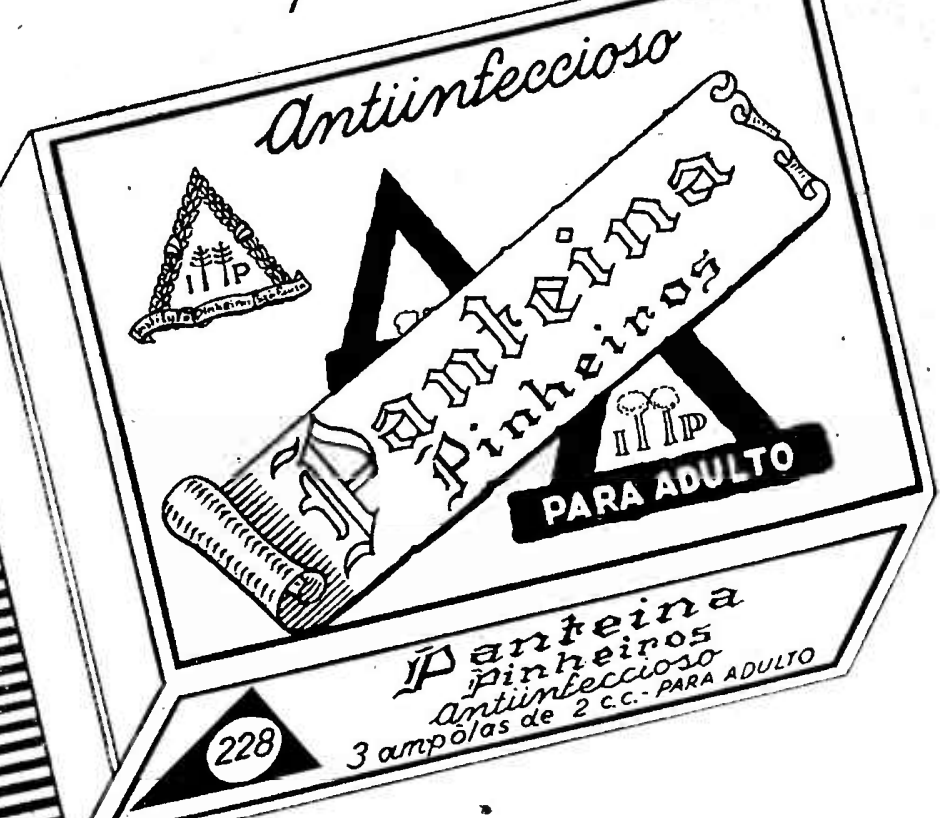

228

3 ampolas as

$$
\begin{gathered}
\text { Gripe, pneumania da } \\
\text { infeeçóes da, } \\
\text { garganta, }
\end{gathered}
$$
estados septicêmicas.

$$
\begin{aligned}
& \text { infeceães } \\
& \text { em } \\
& \text { geral. } \\
& \text { 1-2 ampolas par dia. } \\
& \text { a juiza dinico. }
\end{aligned}
$$

em injescio subcutânea.

Para criansa- Caila de 3 ampölas de 1 c.c. Para adulto. Caixco 